\title{
Conservation of HP1 and methylated H3 histones as heterochromatic epigenetic markers in the holocentric chromosomes of the cabbage moth, Mamestra brassicae (Lepidoptera)
}

\author{
FEDERICA BORSATTI and MAURo MANDRIOLI* \\ Dipartimento di Biologia Animale, Università di Modena e Reggio Emilia, Via Campi 213/d, 41100 Modena, Italy; \\ e-mail: mandriol@unimo.it
}

Key words. Holocentric chromosomes, heterochromatin, HP1, histone H3 methylation, cabbage moth, Lepidoptera, Mamestra brassicae

\begin{abstract}
The methylated H3 histone and heterochromatin protein 1 (HP1) are markers of heterochromatin in several eukaryotes possessing monocentric chromosomes. In order to confirm that these epigenetic markers of heterochromatin are evolutionary conserved, the distribution of methylated H3 histones and HP1 homologues on the holocentric chromosomes of the cabbage moth Mamestra brassicae (Lepidoptera) were studied. In particular, PCR experiments with degenerated primers identified a HP1 homologue (called MbHP1) in the M. brassicae genome. Sequencing showed that the MbHP1 gene is $737 \mathrm{bp}$ long including a $102 \mathrm{bp}$ 5'UTR and a $635 \mathrm{bp}$ coding portion (comprising an $80 \mathrm{bp}$ intron). The MbHP1 peptide consisted of 184 amino acids, had a $20 \mathrm{kDa}$ molecular mass and a net negative charge. At the structural level, it showed an $\mathrm{N}$ terminal chromo-domain and a chromo-shadow-domain at the $\mathrm{C}$ terminus linked by a short hinge region. At the cytogenetic level, MbHP1 was located exclusively in the heterochromatic regions of the chromosomes. The same heterochromatic regions became labelled after immuno-staining with antibodies against $\mathrm{H} 3$ histone methylated at lysine 9, reinforcing the hypothesis that this modified histone is essential for HP1 binding. Our data, as a whole, confirm that heterochromatic components and markers are evolutionary conserved both in mono- and holocentric chromosomes despite the difference in the distribution of heterochromatin on chromosomes.
\end{abstract}

\section{INTRODUCTION}

Studies on organisms ranging from yeast to vertebrates strongly suggest that histones and their post-translational modifications play a pivotal role in the assembly of heterochromatin. In particular, a major advance in the understanding of how heterochromatin is formed came with the observation by Jenuwein and colleagues that the $\mathrm{Su}(\mathrm{Var}) 39 \mathrm{H}$ gene, which was detected originally as a mutant allele that suppresses position-effect variegation in Drosophila, encodes a histone methyltransferase (HMT) protein (Rea et al., 2000). The specificity of the $\mathrm{Su}($ Var) 39 HMT for lysine 9 of histone H3 provided the first evidence that methylation of this residue is directly involved in heterochromatin formation.

Several papers indicate that methylation is just one type of post-translational modification that occurs in histones and in according to the "histone code" hypothesis such covalent modifications may generate a "code", which can be "deciphered" by chromosomal proteins and thereby regulate tissue-specific patterns of gene expression (Strahl \& Allis, 2000; Turner, 2000; Nakayama et al., 2001; Zhang \& Reinberg, 2001). In particular, methylation at lysine 9 in histone $\mathrm{H} 3(\mathrm{Me} 9 \mathrm{H} 3)$ represents one of the most robust histone modifications (Jenuwein \& Allis, 2001).

Current theories suggest that in addition to the direct effects of these modifications on nucleosome structure, the modified residues also act as recognition motifs that mediate interactions with transcription factors and chromatin binding proteins. In particular, several experiments indicate that methylated $\mathrm{H} 3$ lysine 9 residues constitute a specific binding target for heterochromatin protein 1 (HP1) (Lachner et al., 2001).

The HP1 class of chromobox genes encodes polypeptides involved in organizing higher order structure of chromatin by linking or anchoring chromatin subunits (James \& Elgin, 1986; Epstein et al., 1992; Eissenberg \& Elgin, 2000; Kellum, 2003). The possible functions of these complexes are wide-ranging and include roles in transcription repression, transgene silencing, chromosome segregation and sex chromosome inactivation (Wang et al., 2000; Jones et al., 2000).

Studies on the structure and epigenetic markers of heterochromatin were performed mainly on organisms with monocentric chromosomes, whereas organisms possessing holocentric chromosomes have been almost neglected. Moreover, the available data derive from few species, which makes the analysis of this topic in a larger range of species more interesting (Cowell et al., 2002). In the present paper, the presence of methylated $\mathrm{H} 3$ histones and HP1 homologue was determined in order to verify if these two heterochromatic markers are evolutionary conserved in the heterochromatin of lepidopteran holokinetic chromosomes.

\footnotetext{
* Corresponding author.
} 


\section{MATERIAL AND METHODS}

Cabbage moth in vitro culture and chromosome preparation

The IZD-MB-0503 cell line of M. brassicae (ATCC number: CRL-8003) was used for all the experiments. Cells were cultured in Ex-Cell 405 medium (JRH Biosciences, Lenexa, KS, USA) at $26^{\circ} \mathrm{C}$.

CRL-8003 cells were spread following a modified version of the method described by Mandrioli (2002). Briefly, cells were kept in a hypotonic solution ( $0.8 \%$ sodium citrate) for about 45 $\mathrm{min}$, then transferred to minitubes and centrifuged at $350 \mathrm{~g}$ for 3 min. A fixative (formaldehyde $4 \%$ in PBS) was successively added to the pellet, which was made to flow up and down for 1 min in a needle of a $1 \mathrm{ml}$ hypodermic syringe. Finally, the pellet was resuspended in $200 \mu \mathrm{l}$ of fresh methanol and $20 \mu \mathrm{l}$ of this suspension was dropped on clean slides and air-dried.

\section{In situ HP1 immunolocalization and C-banding}

In situ immunostaining experiments were performed with an anti-Drosophila melanogaster HP1 antibody diluted 1:500 (a kind gift from R. Kellum) (Huang et al., 1998) and an antihistone H3 methylated at lysine 9 (Me9H3) (Upstate, Cambridge, UK) diluted 1:250 following the protocol of Bongiorni et al. (2001) but with the difference that a FITC-conjugated secondary antibody (diluted 1:500) was used instead of an Alexaconjugated-one.

C-banding was performed according to the technique of Sumner (1972). After the treatment, slides were stained with 4'6'-diamidino-2-phenylindole (DAPI) as described by Donlon \& Magenis (1983).

Immunofluorescent preparations were observed using a Zeiss Axioplan epifluorescence microscope equipped with a $100 \mathrm{~W}$ mercury light source. Photographs of the fluorescent images were taken using a CCD camera (Spot, Digital Instrument, Madison, USA) and using the Spot software supplied with the camera and processed using Adobe Photoshop software (Adobe Systems, Mountain View, CA).

\section{DNA and RNA extraction}

DNA extraction from cultured CRL-8003 cells was performed using the standard protocol cited in Mandrioli (2002). RNA extraction was performed with the SV Total RNA Isolation System (Promega Corporation, Madison, USA) following the supplier's instructions.

\section{HP1 amplification, sequencing and cloning}

Amplification of HPl gene from the cabbage moth genome was performed with primers designed using the $D$. melanogaster $H P 1$ coding sequence (sequence access code $D R O H P 1$ ) as a reference sequence. However, the designed primers were degenerated according to the alignment results of DROHP1 with other HP1 genes available in Genbank in order to improve primers ability to amplify a HP1 gene in Lepidoptera. The designed primer sequences are: $\mathrm{F} 1_{\mathrm{HPI}}$ (5'-CCGTGGAAAARATMATSGAC -3') starting at nucleotide 74 and $\mathrm{R} 1_{\mathrm{HP1}}$ (5'ACCATTTCHGCTTVGTCRAC-3') starting at nucleotide 530 in the DROHPl sequence. The same primers were used in RT-PCR experiments that were made with the Access RT-PCR System (Promega), according to the supplier's instructions.

The complete gene sequence of $M$. brassicae HP1 homologue $(\mathrm{MbHP} 1)$ was obtained by Rapid Amplification of cDNA Ends (RACE), according to Frohman (1990), using the same primers as previously used for PCR and RT-PCR. M. brassicae HP1 sequence was confirmed by inverse PCR (Borsatti et al., 2004) that also allowed the identification of introns and exons within the amplified gene.

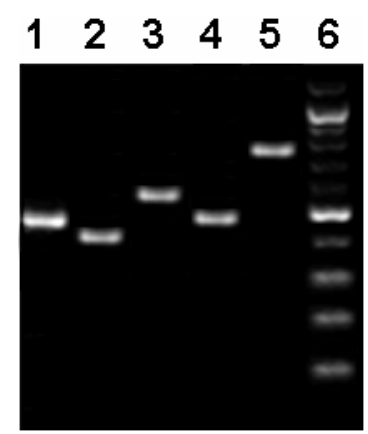

Fig. 1. PCR amplification of an internal fragment of the HP1 gene from the $M$. brassicae genome obtained by using direct PCR (lane 1) and RT-PCR (lane 2). HP1 gene sequence was completed by 5' and 3' RACE (lane 3 and 4) and confirmed by inverse PCR (lane 5). The molecular weight of the amplified fragments was evaluated using the $100 \mathrm{bp}$ ladder DNA marker (lane 6).

The MbHPl was cloned using the "pGEM-T-easy" cloning kit (Promega Corporation, Madison, USA) according to the manufacturer's protocol and sequenced at the "BMR-University of Padova". Sequence analysis was performed using GCG software (GCG Computer Group, Madison, USA). Sequence phosphorylation was evaluated using the NetPhos 2.0 server that produces neural network predictions for serine, threonine and tyrosine phosphorylation sites in eukaryotic proteins (Blom et al., 1999).

\section{Protein purification and western blotting}

In vitro production and purification of $M$. brassicae HP1 protein were performed using the PinPoint System (Promega) according to manufacturer's protocol. Whole protein extraction

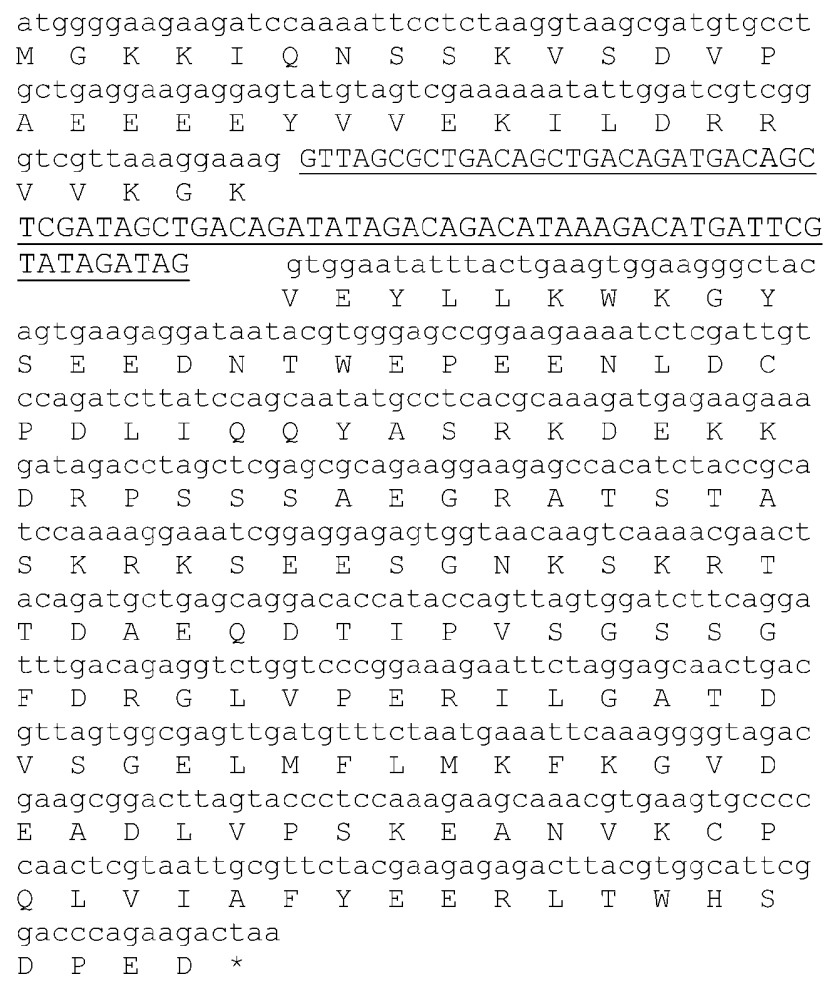

Fig. 2. M. brassicae HP1 coding sequence consisted of a 635 coding portion constituted by two exons and an 80 bp long intron. Intron sequence is underlined. 
(A) HP1_termop

(B) swi $\overline{6}$ s.po

(C) $\mathrm{MbHp} \overline{1}$ mame

(D) Hpl dros m

(E) Hpl_dros_v

(F) pchet 1

(G) pchet2

(H) HP1_al mus

(I) Hp1_bet_mu

(J) Hp1 gam mu

(K) $\mathrm{CHC} \overline{\mathrm{B}} 1$ gāll

(L) X-Hp1 xeno

(M) HP1 Dānio

(N) Hp1-alpha

(O) Hp1 beta_h

(P) Hp1_gammā

(A) HP1_termop

(B) swi $\overline{6}$ S. po

(C) $\mathrm{MbHp} \overline{1}$ mame

(D) Hp1 dros m

(E) Hp1_dros_v

(E) pchèt1

(G) pchet2

(H) HP1 al mus

(I) Hp1_bet_mu

(J) Hp1 gam mu

(K) $\mathrm{CHC} \bar{B} 1$ gāll

(L) X-Hp1 xeno

(M) HP1 Dānio

(N) Hp1 alpha

(O) Hpl beta h

(P) Hp1_gammā

(A) HP1_termop

(B) swi $\overline{6}$ S.po

(C) $\mathrm{MbHp} \overline{1}$ mame

(D) Hpl dros m

(E) Hp1 ${ }^{-}$dros_-

(E) pchet 1

(G) pchet2

(H) HP1_al mus

(I) $\mathrm{Hpl}{ }^{-}$bet mu

(J) $\mathrm{Hpl}^{-} \mathrm{gam}{ }^{-} \mathrm{mu}$

(K) $\mathrm{CHC} \overline{\mathrm{B}} 1$ gāll

(L) X-Hp1 xeno

(M) HP1 Dānio

(N) Hp1 alpha

(O) Hp1_beta_h

(P) Hp1_gammā
1

10 RRSSTSKRSVIDDDSEPELPSMTKEAIASHKADSGSSDNEVESDHESKSSSKKLKENAKE

$1----------------------$ MGKKIQN----SSKVSDVPAE

1 --------------------------------MGKKIDNPE--SSAKVSDAEEE

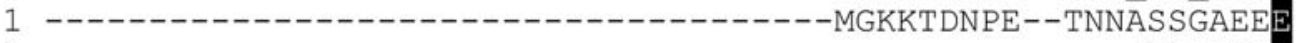

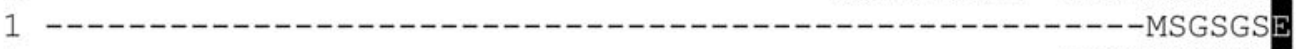

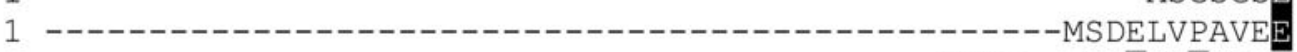

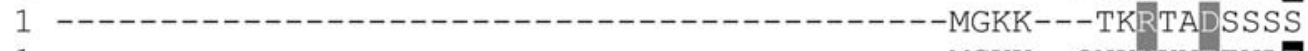

1 ---------------------------------MGKK--QNKKKVEEVLE

10 YKALL--IQYIKTNLKYELHMPGKGLILGKYILRGVCKGQSEITGAN--NAQQLSEEAEI

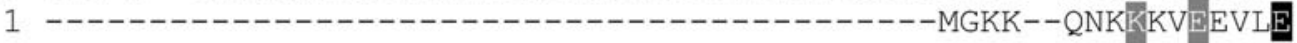

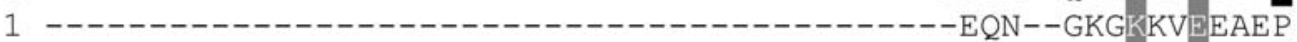

1 -------------MSQPTETVSDAPSVTEEVSPDSKLAATAGKK--QTKKKVEDVVE

$1-----------------------------------M G K K---T K R T A D S S S S$

$1-------------------------------M G K K--Q N K K K V E E V L E$

121 QRCCR--RWWIALKFQTTQPFPISSFFIPVKKQLNTLQGTLSLDDEN--NIFKVVEKRHQ

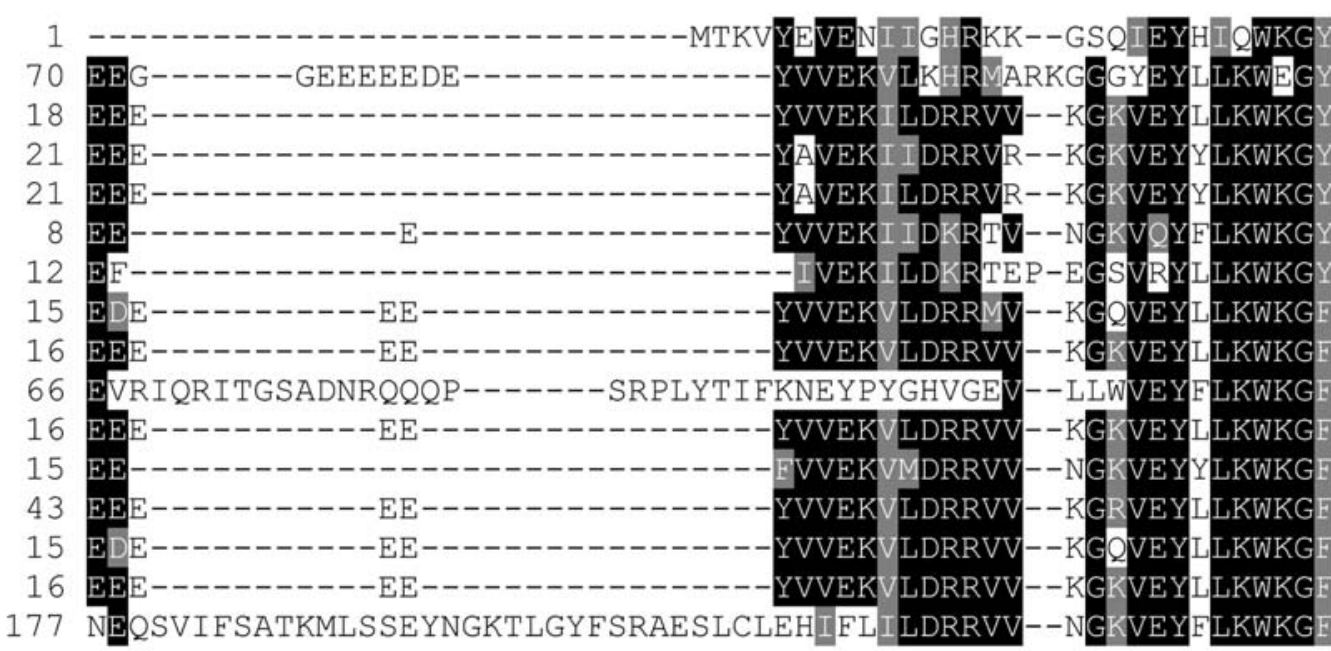

30 SL-KQATYEPAKNIL-DKNMLKKYQQRHLLSNDKPQ-------TPIKKSIKKGASTHQT 108 DDPSDNTWSSEADCSGCKQLIEAYWNEHGGRPEPSKRKRTARPKKPEAKEPSPKSRKTDE 46 SE-EDNTWEPEENLD-CPDLIQQYAS-RKDE---KKD---------RPSSSAEG-RAT49 PE-TENTWEPENNLD-CEDLIQQYEASRKDEEKSAAS------KK-DRPSSSAKA-KETQ 49 AE-TENTWEPEGNLD-CQDLIQQYELSRKDEANAAASSSSSSSKK-ERPGSSTKV-KETG 36 DE-SENTWEPHENLE-CPELIAEEERKWEKKQE-----------------EKK-NARK 39 GD-EDNTWEPPENMD-CEDLIEELQKKLSKPKKRRKR------------IIEPDD-DGDS 45 SE-EHNTWEPEKNLD-CPELISEFMKKYKKMKEGENN-----------KPREKS-EGNK 46 SD-EDNTWEPEENLD-CP LIAEFLQSQKTAHE---------------TDKS-EGGK

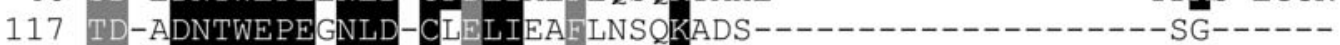
46 SD-EDNTWEPEENLD-CPDLIAEELQSQKTAHE-----------------SEKS-EGSK 42 TD-SDNTWEPEENLD-CPELIEAFLNSQKAGK----------------EKP-DSNK

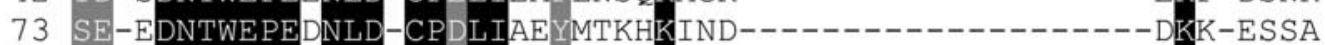
45 SE-EHNTWEPEKNLD-CPELISE EMKKYKKMKEGENN-----------KPREKS-ESNK 46 SD-EDNTWEPEENLD-CPDLIAEELQSQKTAHE---------------TDKS-EGGK 235 TD-ADNTWESEENLH-CPELIEAELNSQKAGK------------------EK--VGTK

Fig. 3. Alignment of MbHP1 amino acid sequence (C) with the HP1 homologues reported in GenBank: T. thermophila heterochromatin-associated protein 1-like (AF079405) (A), S. pombe swi6 (SPSWI6) (B), D. melanogaster HP1 (DROHP1) (D), D. virilis HP1-like (DROHTCHRPI) (E), P. citri pchet1 (F) and pchet2 (G), M. musculus HP1 alpha (AF216290) (H), beta (CBX1) (I) and gamma (LOC333074) (J), G. gallus mRNA for chromobox protein HP1-like (AB005617) (K), X. laevis HP1 alpha (AY168927) (L), D. rerio HP1-like gene (BC045443) $(\mathrm{M})$ and human HP1 alpha $(\mathrm{CBX} 5)(\mathrm{N})$, beta $(\mathrm{CBX} 1)(\mathrm{O})$ and gamma $($ LOC341009) (P). 
(A) HP1 termop

(B) swi $\overline{6}$ s._po

(C) $\mathrm{MbHp} \overline{1}$ mame

(D) Hp1_dros_m

(E) Hp1_dros_v

(F) pchèt1

(G) pchet2

(H) HP1 al mus

(I) Hp1_bet_mu

(J) Hp1_gam_mu

(K) $\mathrm{CHC} \overline{\mathrm{B}} 1$ gāll

(L) X-Hp1_xeno

(M) HP1 Dānio

(N) $\mathrm{Hp1}^{-}$alpha

(O) Hp1_beta_h

(P) Hp1_gammā

(A) HP1_termop

(B) swi $\overline{6} \mathrm{~s} . \mathrm{po}$

(C) $\mathrm{MbHp} \overline{1}$ mame

(D) Hpl dros m

(E) Hp1_dros_v

(E) pchēt1

(G) pchet2

(H) HP1_al_mus

(I) Hp1 bet mu

(J) $\mathrm{Hpl}^{-} \mathrm{gam}{ }^{-} \mathrm{mu}$

(K) $\mathrm{CHC \overline {B }} 1$ gāll

(L) X-Hp1_xeno

(M) HP1 Dānio

(N) Hp1 alpha

(O) Hp1_beta_h

(P) Hp1_gammā

(A) HP1_termop

(B) swi $\overline{6} \mathrm{~s} . \mathrm{po}$

(C) $\mathrm{MbHp} \overline{1}$ mame

(D) Hp1_dros_m

(E) Hp1_dros_v

(F) pchēt1

(G) pchet2

(H) HP1 al mus

(I) $\mathrm{Hpl}{ }^{-}$bet mu

(J) Hp1 gam mu

(K) $\mathrm{CHCB} 1$ _gàl

(L) X-Hp1 xeno

(M) HP1 Dānio

(N) Hp1-alpha

(O) Hp1_beta_h

(P) Hp1 gammā

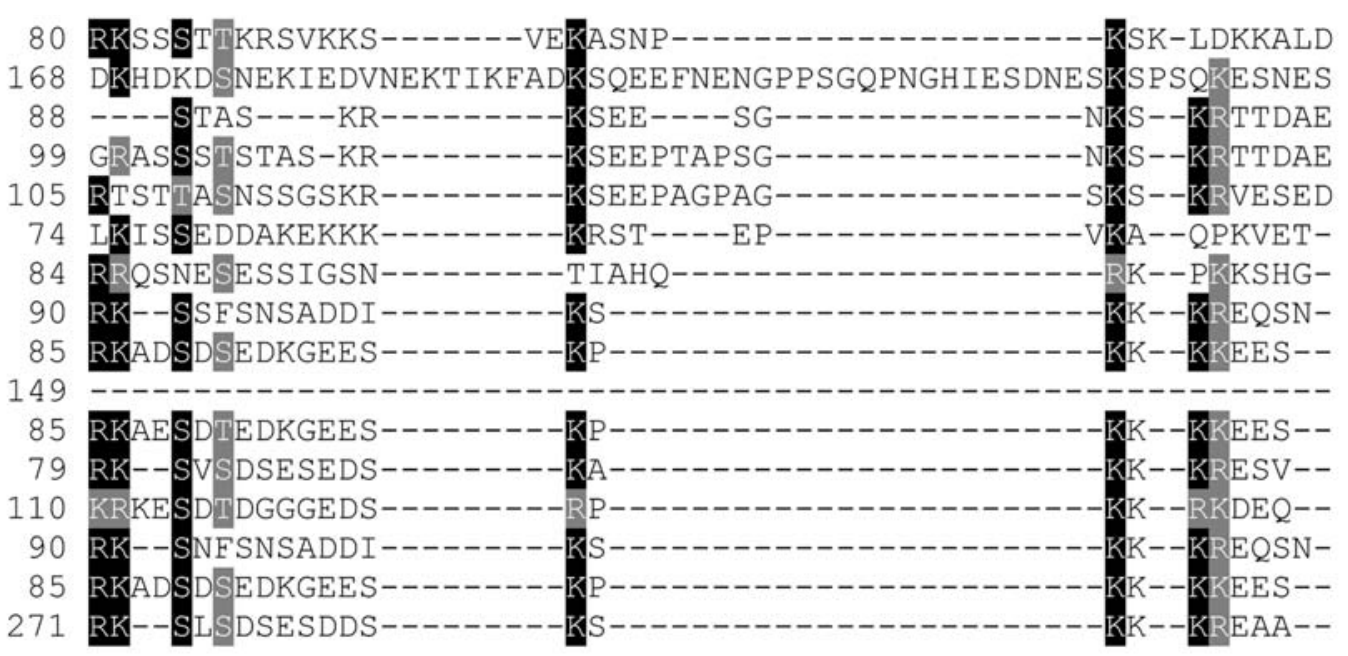

Fig. 3 continued.

from M. brassicae cells and D. melanogaster SL2 cells was performed in $125 \mathrm{mM}$ Tris- $\mathrm{HCl} \mathrm{pH}$ 6.8, 2\% SDS, 5\% glycerol and $1 \% \beta$-mercaptoethanol. Electophoresis on SDS-PAGE gel and blotting on polyvinylidene difluoride (PVDF) membrane were carried out following Sambrook et al. (1989). Immunoblotting with the anti-HP1 was performed according to Cowell et al. (2002). 


\section{RESULTS}

\section{Identification of a HP1 homologue in the cabbage moth}

Amplification performed with primers $\mathrm{F} 1_{\mathrm{HP} 1}$ (5'CCGTGGAAAARATMATSGAC-3') and R1 $1_{\mathrm{HP} 1}$ (5'ACCATTTCHGCTTVGTCRAC-3') revealed a 480 bp long HP1 fragment in the cabbage moth genome (Fig. 1, lane 1). RT-PCR experiments, using the same primers, showed a 400 bp long fragment (Fig. 1, lane 2) assessing the presence of an intron sequence.

In order to obtain a full-length fragment of M. brassicae HP1 gene coding sequence (called MbHP1), RACE experiments were performed: amplification of the 5 , terminal revealed a 566 bp long fragment (Fig. 1, lane 3), whereas amplification of the 3 ' terminal indicated the presence of a $491 \mathrm{bp}$ long fragment (Fig. 1, lane 4). MbHP1 sequence was confirmed by inverse PCR amplification (Fig. 1, lane 5). In particular, inverse PCR allowed us to verify the presence of an intron within the HPl gene.

Sequencing of all the fragments showed that $M b H P 1$ is a 737 bp long gene including a 102 bp long 5'UTR and a $635 \mathrm{bp}$ coding portion (constituted by two exons and an 80 bp long intron). No 3' UTR was observed (Fig. 2).

$M$. brassicae HP1 coding sequence was aligned with HPl-like sequences available in Genbank, including those of Schizosaccharomyces pombe swi6 (SPSWI6), Tetrahymena thermophila heterochromatin-associated protein 1-like (AF079405), Drosophila melanogaster HP1 (DROHP1), Drosophila virilis HP1-like (DROHTCHRPI), Planococcus citri pchet1 and pchet2, Homo sapiens HP1 alpha (CBX5), beta (CBX1) and gamma (LOC341009), Mus musculus HP1 alpha (AF216290), beta (CBX1) and gamma (LOC333074), Xenopus laevis HP1 alpha (AY168927), Gallus gallus mRNA for chromobox protein HPl-like (AB005617) and Danio rerio HPl-like gene (BC045443). Alignment showed a sequence similarity ranging from 45.4 to $64.5 \%$ if performed using the total gene length, whereas it ranged from 84 to $96 \%$ if made with the chromo-domain (CD) sequence only. A similar range of sequence similarity was found when the chromo-shadow domains (CSDs) were aligned.

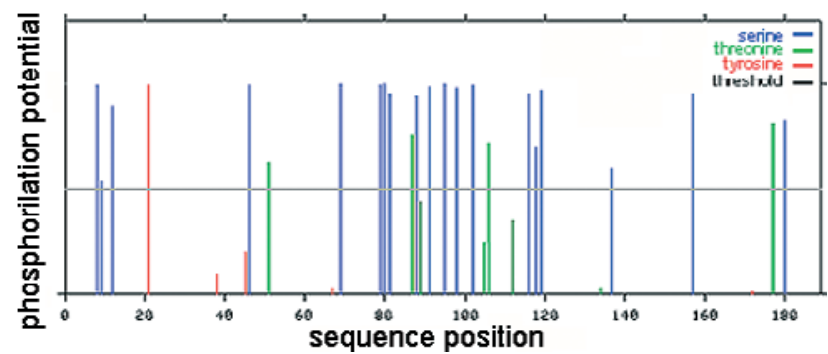

Fig. 4. Neural network predictions of the serine, threonine and tyrosine phosphorylation sites in M. brassicae HP1 protein indicated the presence of several putative site for phosphorylation in the serine and threonine residues.
The putative MbHP1 peptide consisted of 184 amino acids and contained a high proportion of negatively charged amino acids that resulted in a the net negative charge of -9 . The predicted molecular mass is $20 \mathrm{kDa}$, which is in accordance to the range reported for HP1-like proteins (Eissenberg \& Elgin, 2000). The overall similarity of MbHP1 peptide with other HP1 peptides in the GenBank ranged from 37 to $85 \%$ (Fig. 3) and was as high as $97 \%$ in both the CD and CSD sequence. In contrast to that reported for the $P$. citri HP1 peptide, MbHP1 contained no internal repeat sequences.

Bioinformatic analysis of the M. brassicae HP1 amino acid sequence indicated the presence of multiple sites with a high serine and threonine phosphorylation potential and just one with a high tyrosine phosphorylation potential (Fig. 4).

\section{Western blotting and immunolocalization of HP1 on cabbage moth chromosomes}

In order to detect HP1 protein in the cabbage moth, western blotting experiments with an antibody that recognize Drosophila HP1 protein were performed as a preliminary step. In particular, immunoblotting was done using a rabbit anti-HP1 antibody against $D$. melanogaster HP1 protein (Huang et al., 1998) (Fig. 5). In the lane containing the protein extract from SL2 Drosophila cells, the HP1 antibody, as expected, recognized an antigen with an apparent molecular weight of $34 \mathrm{kDa}$ (Eissenberg \& Elgin, 2000) (Fig. 5, lane 2). In the lane containing the whole protein extract from $M$. brassicae cells a single band of about $20 \mathrm{kDa}$ was observed (Fig. 5, lane 3). If the anti-HP1 antibody is incubated with the in vitro produced

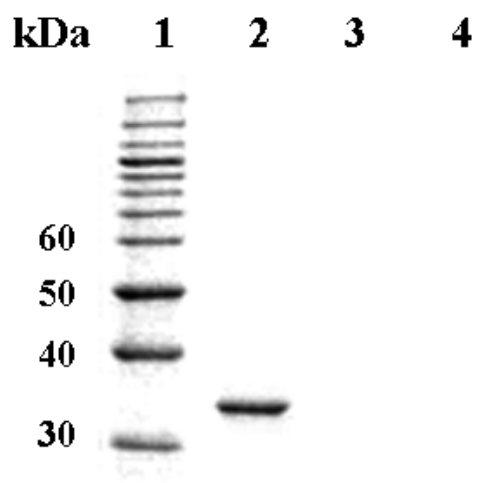

20

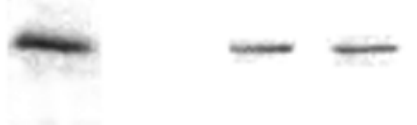

Fig. 5. Western blot of protein extracts from D. melanogaster (lane 2) and M. brassicae (lane 3) probed with fly anti-HP1 antibody as the primary one and goat anti-mouse IgG-HRP as secondary one. Note that the band detected in D. melanogaster migrates with an apparent MW of $34 \mathrm{kDa}$ (as expected on the basis of previous papers) and the presence of a unique band of approximately $20 \mathrm{kDa}$ in the cabbage moth extract. MbHP1 produced in vitro (lane 4) has the same MW and it is recognized by Drosophila anti-HP1 antibody. The MW of each protein was deduced according to the standard weight marker (lane 1). 

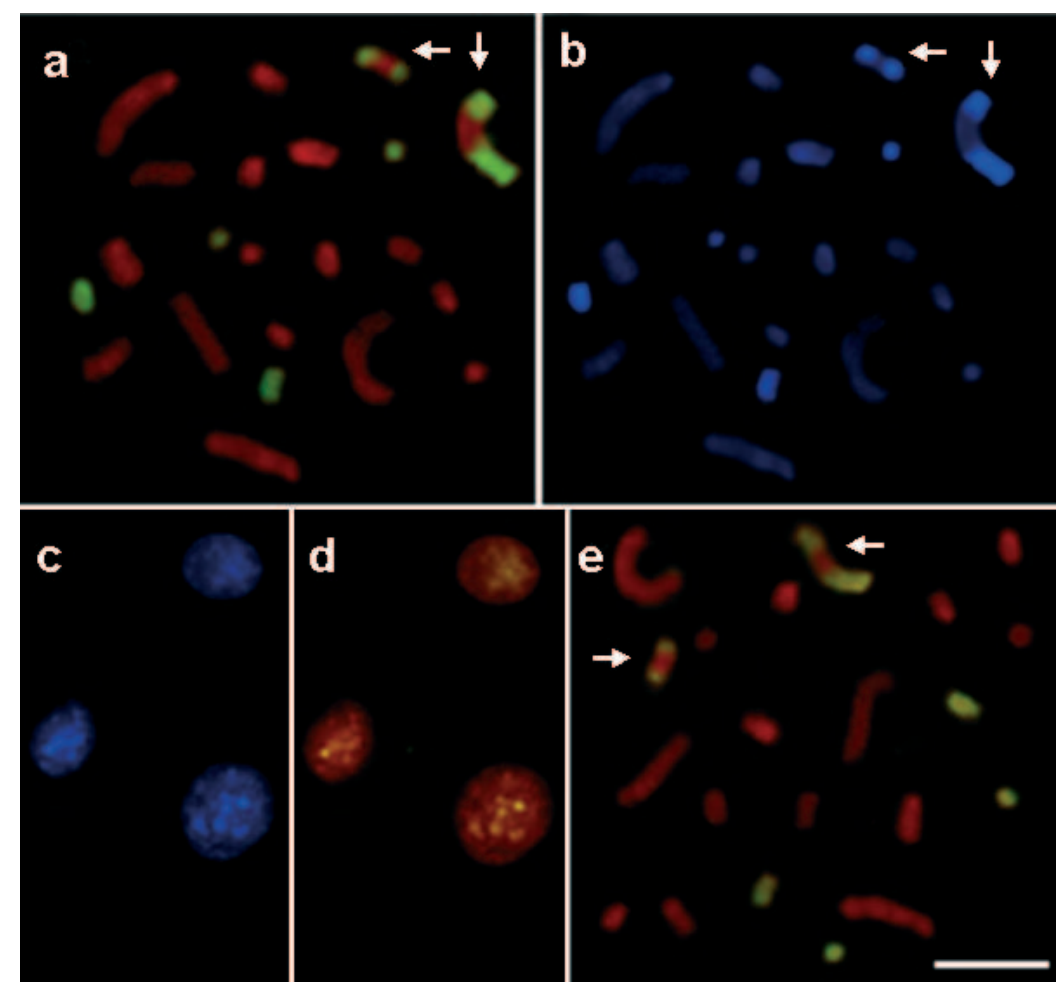

Fig. 6. In situ immunofluorescence of cabbage moth chromosomes ( $a, b$ and e) and nuclei (c, d) showed that HP1 is clustered on the heterochromatic regions of the sex chromosomes (indicated by arrows) and chromosome pairs 7 and 10 as deduced by $\mathrm{C}$ banding (b, c). The same regions resulted brightly fluorescent after immunostaining with anti-histone H3 methylated at lysine 9 (e).

HP-1 antibody before blotting (HP1 depletion), no signal was observed. These data indicate that anti-Drosophila HP1 specifically recognizes an HP1 protein in the cabbage moth extract.

To confirm this hypothesis, MbHP1 protein was produced in vitro from the cloned $M b H P 1$ gene and analysed on immunoblot (Fig. 5, lane 4). Western blotting confirmed that Drosophila anti-HP1 is able to recognize MbHP1 that was produced in vitro.

In situ immunolocalization of chromosomes showed that HP1 proteins were not scattered along all M. brassicae chromosomes but were located in several chromosomal regions of the $\mathrm{Z}$ and $\mathrm{W}$ sex chromosomes and chromosome pairs 7 and 10 (Fig. 6a). C banding performed on the slides previously used for HP1 immunolocalization (Fig. 6b) revealed that $\mathrm{C}$-banded constitutive heterochromatin and HP1 positive chromosomal regions were overlapped in the cabbage moth complement and interphase nuclei (Fig. 6c, d).

\section{Immunolocalization of $\mathrm{Me} 9 \mathrm{H3}$ on cabbage moth chromosomes}

Immunolocalization with anti-Me9H3 was used to reveal the distribution of histone $\mathrm{H} 3$ methylated at lysine 9 on M. brassicae chromosomes. The Me9H3 was found to be located only in the heterochromatic regions of the two sex chromosomes ( $\mathrm{Z}$ and $\mathrm{W}$ ) and on chromosome pairs 7 and 10 (Fig. 6e). In view of the previous results obtained with the anti-HP1, Me9H3 and HP1 are similarly located on $M$. brassicae chromosomes.

\section{DISCUSSION}

Sequencing of the M. brassicae HPl gene (called $M b H P 1$ ) showed that it was 737 bp long including a 102 bp long 5'UTR and a 635 bp coding portion (constituted by two exons and an $80 \mathrm{bp}$ long intron). The MbHP1 protein had a $\mathrm{N}$ terminal chromo-domain and a chromoshadow domain at the $\mathrm{C}$ terminus. A peculiarity of $\mathrm{MbHP} 1$ is that the hinge region is particularly short.

The putative MbHP1 peptide consisted of 184 amino acids, had a predicted molecular mass of $20 \mathrm{kDa}$ and a net negative charge (-9). All these features are consistent with those reported for HP1-like proteins. The overall similarity of MbHP1 with the other HP1-polypeptides in the GenBank ranged from 37 to $85 \%$ and was particularly high (at least $78 \%$ ) with $D$. melanogaster and $D$. virilis HP1s and with alpha and beta isoforms of human and mouse HP1. This is particularly interesting since all of these HP1 molecules are reported to have heterochromatic rather than euchromatic localizations (as reported for mammalian HP1 $\gamma$ ) (Eissenberg et al., 1994) suggesting that HP1 has specific functions in heterochromatin assembly in Lepidoptera.

Drosophila HP1 is multiply phosphorylated by serinethreonine kinases and consensus CKII kinase target sites are found near the $\mathrm{N}$ - and $\mathrm{C}$ terminal ends and in the hinge domain (Eissenberg et al., 1994). The occurence of phosphorylation at different sites is thought to be functionally important since phosphorylation could regulate the assembly of HP1 into higher order chromatin struc- 
ture (Koike et al., 2000). Bioinformatic analysis of $M$. brassicae HP1 amino acid sequence indicated the presence of multiple sites with a high serine phosphorylation potential in the hinge and in the chromo-domain, whereas the unique sequence with a high tyrosine phosphorylation potential is located within the chromo-domain. Sequences with high threonine phosphorylation potential were found within the hinge and in the chromo-shadow-domain. The general pattern and prevalence of serine and threonine residues observed in the cabbage moth HP1 are consistent with the consensus kinase target sites reported in Drosophila (Zhao et al., 2000).

Western blotting results showed that the anti-HP1 antibody raised against $D$. melanogaster HP1 could be effectively used to localize HP1 on $M$. brassicae chromosomes. The specificity of the antibody was verified not only by the presence of a unique band in the immunoblotting performed on the whole cabbage moth protein extract but also by the ability of Drosophila anti-HP1 to recognize the in vitro purified $M$. brassicae HP1 peptide and by the depletion of the antibody obtained by incubating anti-HP1 with $M b \mathrm{HP} 1$ before western blotting. As a whole, western blotting experiments indicated that the anti-HP1 tested was useful for HP1 immunolocalization.

Several papers report that the binding of HP1 to heterochromatic regions is mediated by $\mathrm{H} 3$ histone methylated at lysine 9 in vertebrates (e.g. Lachner et al., 2001). In view of this, the immuno-fluorescence experiments were performed using an antibody specific for Me9H3, which indicate that cabbage moth constitutive heterochromatin is enriched in $\mathrm{H} 3$ histone methylated at lysine 9. This epigenetic mark is therefore a true heterochromatin marker not only for vertebrate but also for insect heterochromatin, as previously reported in the dipteran $D$. melanogaster and the homopteran $P$. citri (Cowell et al., 2002).

Our results, as a whole, indicate that $\mathrm{HP} 1$ and $\mathrm{Me} 9 \mathrm{H} 3$ are both true markers of $M$. brassicae heterochromatin and confirmed that these two heterochromatic tags are evolutionary conserved in lepidopteran holocentric chromosomes. The heterochromatin of holocentric chromosomes, therefore, shows several common features with that of monocentric chromosomes since both contain ATrich satellite DNAs, transposable elements, HP1 proteins and methylated histones (e.g. Ohbayashi et al., 1998; Mandrioli et al., 1999; Cowell et al., 2002; Mandrioli, 2002; Mandrioli, 2003a, b; Mandrioli et al., 2003).

ACKNOWLEDGEMENTS. We are greatly indebted to R. Kellum for sending us the Drosophila anti-HP1 antibody and critically reviewing the manuscript. This work is supported by the grant "F.A.R." from the University of Modena and Reggio Emilia (M.M.).

\section{REFERENCES}

Blom N., Gammeltoft S. \& Brunak S. 1999: Sequence- and structure-based prediction of eukaryotic protein phosphorylation sites. J. Mol. Biol. 294: 1351-1362.

Bongiorni S., Mazzuoli M., Masci S. \& Prantera G. 2001: Facultative heterochromatization in parahaploid male mealy- bugs: involvement of a heterochromatin-associated protein. Development 128: 3809-3817.

Borsatti F., Azzoni P. \& Mandrioli M. 2004: Identification of a new hobo element in the cabbage moth, Mamestra brassicae (Lepidoptera). Hereditas 139: 151-155.

Cowell I.G., Aucott R., Mahadevaiah S.K., Burgoyne P.S., Huskisson N., Bongiorni S., Prantera G., Fanti L., PimpInelli S., Wu R., Gilbert D.M., Shi W., Fundele R., Morrison H., JePpesen P. \& Singh P.B. 2002: Heterochromatin, HP1 and methylation at lysine 9 of histone $\mathrm{H} 3$ in animals. Chromosoma 111: 22-36.

Donlon T.A. \& MAGENIS R.E. 1983: Methyl-green is a substitute for distamycin A in the formation of distamycin A/DAPI C-bands. Hum. Genet. 65: 144-146.

Eissenberg J.C. \& Elgin S.C.R. 2000: The HP1 protein family: getting a grip on chromatin. Curr. Opin. Genet. Dev. 10: 204-210.

Eissenberg J.C., Ge Y.W. \& Hartnett T. 1994: Increased phosphorylation of HP1, a heterochromatin-associated protein of Drosophila, is correlated with heterochromatin assembly. $J$. Biol. Chem. 269: 21315-21321.

Epstein H., James T.C. \& Singh P.B. 1992: Cloning and expression of Drosophila HP1 homologues form a mealybug, Planococcus citri. J. Cell Sci. 101: 463-474.

Frohman M.A. 1990: RACE: Rapid amplification of cDNA ends. In Innis D.A., Gelfand D.H. \& Snisky J.J. (eds): PCR Protocols. Academic Press, San Diego, pp. 28-38.

Huang D.W., Fanti L., PaK D.T.S., Botchan M.R., Pimpinelli S. \& Kellum R. 1998: Distinct cytoplasmic and nuclear fractions of Drosophila heterochromatin protein 1: their phosphorylation levels and associations with origin recognition complex proteins. J. Cell Biol. 142: 307-318.

JAMES T.C. \& ELGIN S.C.R. 1986: Identification of non-histone chromosomal protein associated with heterochromatin in Drosophila and its gene. Mol. Cell. Biol. 6: 3862-3872.

Jones D.O., Cowell I.G. \& Singh P.B. 2000: Mammalian chromo domain proteins: their role in genome organization and expression. Bioessays 22: 124-137.

Jenuwein T. \& Allis C.D. 2001: Translating the histone code. Science 293: 1074-1080.

Kellum R. 2003: HP1 complexes and heterochromatin assembly. Curr. Top. Microbiol. Immunol. 274: 53-77.

Koike N., Maita H., Taira T., Ariga H. \& Iguchi-Ariga S.M. 2000: Identification of heterochromatin protein 1 (HP1) as a phosphorylation target by Pim-1 kinase and the effect of phosphorylation on the transcriptional repression function of HP1. FEBS Lett. 467: 17-21.

Lachner M., O'Carroll D., Rea S., Mechtler K. \& Jenuwein T. 2001: Methylation of histone H3 lysine 9 creates a binding site for HP1 proteins. Nature 410: 116-120.

MandRIoli M. 2002: Cytogenetic characterization of telomeres in the holocentric chromosomes of the lepidopteran Mamestra brassicae. Chromosome Res. 9: 279-286.

MANDRIOLI M. 2003a: Identification and chromosomal localization of mariner-like elements in the cabbage moth Mamestra brassicae (Lepidoptera). Chromosome Res. 11: 319-322.

MANDRIOLI M. 2003b: Identification and molecular characterization of R1 transposable elements in the cabbage moth Mamestra brassicae. Caryologia 56: 155-160.

Mandrioli M., Bizzaro D., Giusti M., Gionghi D., Manicardi G.C. \& BiAnchI U. 1999: Cytogenetic and molecular characterization of a highly repeated DNA sequence in the peach potato aphid Myzus persicae. Chromosoma 108: 436-442.

Mandrioli M., Manicardi G.C. \& Marec F. 2003: Cytogenetic and molecular characterization of the MBSAT1 satellite DNA 
in holokinetic chromosomes of the cabbage moth, Mamestra brassicae (Lepidoptera). Chromosome Res. 11: 51-56.

Nakayama J., Rice J.C., Strahl B.D., Allis C.D. \& Grewal S.I. 2001: Role of histone H3 lysine 9 methylation in epigenetic control of heterochromatin assembly. Science 292: 110-113.

Ohbayashi F., Shimada T., Sugasaki T., Kawai S., Mita K., OSHIKI T. \& ABE H. 1998: Molecular structure of the copialike retrotransposable element Yokozuna on the $\mathrm{W}$ chromosome of the silkworm, Bombyx mori. Genes Genet. Syst. 73: $345-352$.

Rea S., Eisenhaber F., O'Carroll D., Strahl B.D., Sun Z.W., Schmid M., Opravil S., Mechtler K., Ponting C.P., Allis C.D. \& JENUWEIN T. 2000: Regulation of chromatin structure by site-specific histone H3 methyltransferases. Nature 406: 593-599.

SAmbrook J., Fritsch E.F. \& Maniatis T. 1989: Molecular Cloning. A Laboratory Manual. Cold Spring Harbor Laboratory Press, Cold Spring Harbor, NY, USA.
Strahl B.D. \& Aluis C.D. 2000: The language of covalent histone modifications. Nature 403: 41-45.

SUMNER A.T. 1972: A simple technique for demonstrating centromeric heterochromatin. Exp. Cell. Res. 75: 304-306.

TURNER B.M. 2000: Histone acetylation and an epigenetic code. Bioessays 22: 836-845.

Wang G., Ma A., Chow C.M., Horsley D., Brown N.R., Cowell I.G. \& Singh P.B. 2000: Conservation of heterochromatin protein 1 function. Mol. Cell. Biol. 20: 6970-6983.

Zhang Y. \& ReInBERG D. 2001: Transcription regulation by histone methylation: interplay between different covalent modifications of the core histone tails. Genes Dev. 15: 2343-2360.

Zhao T., Heyduk T. \& Eissenberg J.C. 2000: Phosphorylation site mutations in heterochromatin protein 1 (HP1) reduce or eliminate silencing activity. J. Biol. Chem. 276: 9512-9518.

Received January 11, 2005; revised and accepted March 17, 2005 